\title{
Effectiveness and Tolerability of Nifedipine GITS in Patients with Chronic Kidney Disease and Uncontrolled Hypertension: A Prospective, Multicenter, Observational Study (ADRENAL)
}

Rong Lv $\cdot$ Jianghua Chen $\cdot$ Huamin Wang $\cdot$ Jijun Wang $\cdot$ Hong Cheng $\cdot$ Rong Li $\cdot$

Wei Li · Tao Zhang $\cdot$ Lixin Wei $\cdot$ Qinkai Chen · Jian Huang $\cdot$ Feng Yu $\cdot$ Shizhong Shen

Henglan $\mathrm{Wu} \cdot$ Cuihong Liu $\cdot$ Fuyuan Hong $\cdot$ Jie Liu $\cdot$ Xiaoru Zhang $\cdot$ Hua Xiao $\cdot$ Wenbin Song

Received: May 24, 2021 / Accepted: June 29, 2021 / Published online: July 30, 2021

(c) The Author(s) 2021

\section{ABSTRACT}

Introduction: Achieving target blood pressure (BP) goals in patients with chronic kidney dis-

Supplementary Information The online version contains supplementary material available at https:// doi.org/10.1007/s12325-021-01850-3.

R. Lv · J. Chen $(\bowtie)$

Kidney Disease Center, The First Affiliated Hospital, College of Medicine, Zhejiang University, 79

Qingchun road, Hangzhou 310003, China

e-mail: chenjianghua@zju.edu.cn

H. Wang

Department of Nephrology, Beijing Huairou

Hospital, Beijing, China

J. Wang

Department of Nephrology, Zaozhuang Municipal

Hospital, Zaozhuang, China

H. Cheng

Department of Nephrology, Beijing Anzhen

Hospital, Capital Medical University, Beijing, China

R. Li

Department of Nephrology, The Second Hospital of

Tianjin Medical University, Tianjin, China

W. $\mathrm{Li}$

Department of Nephrology, The Affiliated Hospital of Shandong University of Traditional Chinese Medicine, Jinan, China ease (CKD) and uncontrolled hypertension is a challenge. Various studies have shown the efficacy of nifedipine gastrointestinal therapeutic system (GITS) $60 \mathrm{mg}$ in patients with hypertension. However, there is a paucity of clinical studies in patients with CKD. Hence, we conducted this study to evaluate the effectiveness and tolerability of nifedipine GITS $60 \mathrm{mg}$ in Chinese patients with CKD and uncontrolled hypertension in real-world clinical settings.

T. Zhang

Department of Nephrology, Weihai Central

Hospital, Weihai, China

L. Wei

Department of Nephrology, Fujian Medical University Union Hospital, Fuzhou, China

Q. Chen

Department of Nephrology, The First Affiliated

Hospital of Nanchang University, Nanchang, China

J. Huang

Department of Nephrology, Jinhua Municipal

Central Hospital, Jinhua, China

F. Yu

Department of Nephrology, Peking University

International Hospital, Beijing, China

S. Shen

Department of Nephrology, Quanzhou First Hospital, Quanzhou, China

H. Wu

Department of Nephrology, The First Hospital of Jiaxing, Jiaxing, China 
Methods: In a prospective, multicenter, observational study, Chinese patients with CKD and uncontrolled hypertension were given nifedipine GITS $60 \mathrm{mg}$ with a primary endpoint of change in office systolic BP (SBP) at 12 weeks. The secondary endpoints included changes at 12 weeks in office diastolic BP (DBP), office SBP and DBP in SBP subgroups (140-160 $\mathrm{mmHg}$ and $\geq 160 \mathrm{mmHg}$ ) and CKD stages subgroups, SBP and DBP control rate, and the adverse events (AEs). Statistical analysis was performed using SAS $^{\circledR}$ version 9.4.

Results: In total, 871 and 622 patients were included in the safety analysis set and efficacy analysis set respectively. The mean office SBP and DBP at baseline were 162.9 and $97.3 \mathrm{mmHg}$, respectively. At week 12, the mean change in SBP was $-24.0 \mathrm{mmHg}(95 \%$ confidence interval $[\mathrm{CI}]-25.32,-22.65 \mathrm{mmHg}$ ); after missing data were accounted for, it was $-23.9 \mathrm{mmHg}$ $(95 \%$ CI $-25.25,-22.60 \mathrm{mmHg}$ ). Marked decreases in DBP, and office SBP and DBP in baseline SBP subgroups as well as CKD stages were observed at week 12. The BP control rate at week 12 was $50.0 \%$. Twenty-three $(2.6 \%)$ patients reported at least one drug-related AEs. No event of hypotension or death occurred during the study.

Conclusion: Nifedipine GITS $60 \mathrm{mg}$ showed effectiveness and tolerability in reducing office

C. Liu

Department of Nephrology, The Third Hospital of

Shijiazhuang, Shijiazhuang, China

F. Hong

Department of Nephrology, Fujian Provincial

Hospital, Fuzhou, China

J. Liu

Department of Nephrology, Handan First Hospital,

Handan, China

X. Zhang

Department of Nephrology, Lishui City People's

Hospital, Lishui, China

H. Xiao · W. Song

Medical Affairs, Bayer Healthcare Limited Company, Beijing, China
SBP and DBP in Chinese patients with CKD and uncontrolled hypertension.

Trial Registration: ClinicalTrials.gov identifier NCT03194633.

Keywords: Chronic kidney disease; Hypertension; Nifedipine GITS; Observational study

\section{Key Summary Points}

Why carry out this study?

It is difficult to achieve target blood pressure (BP) goals in patients with chronic kidney disease (CKD) and uncontrolled hypertension.

Nifedipine gastrointestinal therapeutic system (GITS) $60 \mathrm{mg}$ has shown effectiveness in patients with hypertension. However, studies in Chinese patients with CKD with nifedipine GITS $60 \mathrm{mg}$ are limited.

We conducted this study to evaluate the effectiveness and tolerability of nifedipine GITS $60 \mathrm{mg}$ in Chinese patients with CKD and uncontrolled hypertension in realworld clinical settings.

\section{What was learned from the study?}

In Chinese patients with CKD and uncontrolled hypertension, nifedipine GITS $60 \mathrm{mg}$ showed effectiveness in reducing office systolic $\mathrm{BP}(\mathrm{SBP})$ and diastolic BP (DPB); the reduction of SBP/ DBP was positively correlated with baseline BP and was not affected by different stages of CKD. The safety analysis revealed its tolerability.

Nifedipine GITS $60 \mathrm{mg}$ might play an essential role in improving the hypertension management practice in patients with CKD, and offer a new therapeutic option. 


\section{INTRODUCTION}

The prevalence of chronic kidney disease (CKD) is gradually increasing, and as per 2017 data, there were 1.2 million deaths that were attributed to CKD globally [1]. Untreated or inadequately controlled hypertension is considered as one of the most important risk factors for the progression of CKD [2], leading to the development of end-stage renal disease (ESRD) in both men and women [3]. Among patients with CKD, hypertension is the most common comorbidity, reported in $67-92 \%$ of patients with CKD [4]. In China, a nationwide survey conducted in the period 2009 to 2010 showed the prevalence of CKD to be $10.8 \%$ (119.5 million), whereas only $12.5 \%$ of them were aware of their condition $[5,6]$. As per the multicenter study conducted in China, $33.1 \%$ of the patients achieved the target blood pressure (BP) control rate of $<140 / 90 \mathrm{mmHg}$ and $14.1 \%$ of the patients achieved the target of $<130 /$ $80 \mathrm{mmHg}$, suggesting a suboptimal control of hypertension in patients with CKD [6].

Treatment of hypertension in patients with CKD to achieve a BP target goal is challenging as they often have severe hypertension, which requires the use of multiple medications or large dosage of antihypertensive agents to achieve target BP goals [7]. The Eighth Joint National Committee (JNC8) guidelines recommend the use of thiazide-type diuretics, calcium channel blockers (CCBs), angiotensin-converting enzyme inhibitors (ACEI), or angiotensin receptor blockers (ARB) as the initial treatment agents for hypertension [8]. CCBs are the most commonly used antihypertensive drugs for Chinese patients with CKD (78\%), the second and third being ARB (42.2\%) and ACEI (18.0\%), respectively, and $16.6 \%$ of patients use diuretics [9]. Several placebo-controlled trials in China employed a dihydropyridine CCB as the firstline drug for the treatment of active hypertension $[10,11]$.

Nifedipine is the prototype of dihydropyridine CCBs and is widely used as first-line therapy in patients with hypertension [12]. However, short-acting, immediate-release formulation required multiple daily dosing and caused rapid vasodilation followed by reflex sympathetic activation, resulting in side effects such as headaches, palpitations, and flushing [13]. This led to the launch of the extendedrelease preparations. The nifedipine gastrointestinal therapeutic system (GITS) is a doublecoated bilayer tablet, which provides a constant release rate for approximately $20-22 \mathrm{~h}$ via a membrane-controlled, osmotic push-pull process [14]. Furthermore, the GITS dosage form provides a relatively constant plasma nifedipine concentration-time profile throughout the 24-h dosing interval with very little peak to trough fluctuation and renal impairment does not affect the half-life [15]. Additionally, no substantial changes with regard to plasma concentrations or bioavailability of nifedipine were detected in patients with impaired kidney function compared with healthy volunteers [16]; hence, dosage adjustment of nifedipine GITS is not required in patients with chronic renal impairment.

The Chinese general practice clinical guideline/expert consensus on the application of long-acting dihydropyridine CCBs in patients with CKD and hypertension recommended that long-acting CCBs (e.g., nifedipine GITS) can protect the renal function and play an important role in the treatment of renal failure [17]. The previously conducted studies such as FOCUS [18] and EXACT trial [19] have demonstrated the efficacy of nifedipine GITS $60 \mathrm{mg}$ very well. However, clinical studies with nifedipine $60 \mathrm{mg}$ in Chinese patients with CKD are limited. We aimed to provide the relevant clinical experience to physicians with nifedipine $60 \mathrm{mg}$. Hence, we conducted this prospective observational study to assess the effectiveness and tolerability of nifedipine GITS $60 \mathrm{mg}$ in a large cohort of patients with CKD and uncontrolled hypertension in real-world clinical settings in China.

\section{METHODS}

\section{Study Design and Population}

A prospective, multicenter, phase 4 , observational study was conducted in 871 patients with 
CKD and uncontrolled hypertension (office systolic blood pressure [SBP] of $\geq 140 \mathrm{mmHg}$ and diastolic blood pressure [DBP] of $\geq 80 \mathrm{mmHg}$ who have received renin-angiotensin system inhibitors (RASIs) or have not received RASIs treatment because of any contraindications), aged 18-70 years from 17 nephrology clinics across China from July 2017 to August 2020 (ClinicalTrials.gov identifier NCT03194633). The study was approved by the ethics committee of First Affiliated Hospital, College of Medicine, Zhejiang University, 2016 Lun Shen No. (80), which is the master ethics committee. Approval was also provided by the institutional review board of the participating study centers (Table S1 in the supplementary material). The study was conducted in accordance with the Helsinki Declaration of 1964 and its later amendments. All patients provided written informed consent before the study initiation.

The inclusion criteria for the study were (1) male and female patients aged 18-70 years; (2) patients diagnosed with CKD (estimated glomerular filtration rate [eGFR] $>15 \mathrm{~mL} / \mathrm{min} /$ $1.73 \mathrm{~m}^{2}$ ) and hypertension without dialysis/renal replacement therapy; (3) patients with uncontrolled hypertension (office $[\mathrm{SBP}] \geq 140 \mathrm{mmHg}$ and $[\mathrm{DBP}] \geq 80 \mathrm{mmHg}$ ) who have received (RASIs) or have not received RASI treatment because of any contraindications; (4) patients who have not received nifedipine GITS $60 \mathrm{mg}$ (once per day) previously; (5) patients for whom the decision to initiate nifedipine GITS $60 \mathrm{mg}$ treatment was made as per the investigator's routine treatment practice; (6) those who provided signed informed consent; and (7) who have not participated in an investigational program with interventions outside of routine clinical practice. Patients were excluded if (1) they had a contraindication to nifedipine GITS according to the approved prescribing information; and (2) they were participating in an investigational program with interventions outside of routine clinical practice at the same time.

\section{Procedures and Data Collection}

Eligible patients received an oral dose of nifedipine GITS $60 \mathrm{mg}$ and attended up to three clinic visits over a 12 -week period. The timing of follow-up visits was not pre-specified and was according to the treating physician's normal practice. Demographic and clinical data were collected from medical records, if available, or by interviewing the patient. Treatment-related data were collected during the initial visit and follow-up visits. Baseline and follow-up visit data for each patient were collected in the electronic case report form.

\section{Study Outcomes and Endpoints}

Effectiveness and safety were the outcomes assessed in this study. Effectiveness of nifedipine GITS $60 \mathrm{mg}$ was evaluated through change in office SBP from baseline to week 12 and was considered as the primary endpoint of the study. The secondary endpoints for the study were change in DBP from baseline to week 12, changes in office SBP and DBP in different SBP subgroups (SBP 140-160 mmHg, $\geq 160 \mathrm{mmHg}$ ), changes in office SBP and DBP in subgroups of CKD stages (stage 1 [eGFR $\geq 90 \mathrm{~mL} / \mathrm{min} /$ $1.73 \mathrm{~m}^{2}$ ], stage 2 [eGFR $60-89 \mathrm{ml} / \mathrm{min} / 1.73 \mathrm{~m}^{2}$ ], stage 3 [eGFR $30-59 \mathrm{~mL} / \mathrm{min} / 1.73 \mathrm{~m}^{2}$ ], stage 4 [eGFR $15-29 \mathrm{~mL} / \mathrm{min} / 1.73 \mathrm{~m}^{2}$ ), and stage 5 $\left[\right.$ eGFR $\left.<15 \mathrm{~mL} / \mathrm{min} / 1.73 \mathrm{~m}^{2}\right]$ ), and the SBP and DBP control rate at week 12 (BP control goal was to maintain an average office SBP $<140 \mathrm{mmHg}$ and $\mathrm{DBP}<90 \mathrm{mmHg}$; maintain an average office SBP $<130 \mathrm{mmHg}$ and $\mathrm{DBP}<80 \mathrm{mmHg}$ when urine albumin excretion rate was $\geq 30 \mathrm{mg} / 24 \mathrm{~h}$ ). Safety outcomes were assessed by the incidence of adverse events (AEs) that were coded by the Medical Dictionary for Regulatory Activities (MedDRA) version 23.0. Information on AEs including treatment-emergent AEs (TEAEs), adverse drug reactions (ADRs), TEAEs leading to dosage adjustment, TEAEs leading to drug interruption, TEAEs leading to drug withdrawal, severe AEs (SAEs), drug-related SAEs, and TEAEs leading to death was summarized by the number of events, the number of subjects, and incidence rate. 


\section{Statistical Analysis}

The statistical analysis of this study is of a descriptive nature. A total of 622 patients were included in the efficacy analysis set (EFF) that will provide the two-sided 95\% confidence interval (CI) at $\pm 1.3 \mathrm{mmHg}$, which is considered to provide enough precision on the estimations of primary endpoint office SBP. Continuous data were described by the number of non-missing patients, number of missing patients ( $N$ miss), and mean. Continuous variables were described by the absolute value and change from baseline per analysis time point, if applicable. For categorical variables, the number and proportion of patients were calculated. The proportions were calculated on the basis of non-missing data. Sensitivity analysis was performed for the missing primary and secondary variables at week 12 by replacing them with the mean of the non-missing values at week 12 . All statistical analyses were performed using SAS $^{\circledR}$ version 9.4 (SAS Institute Inc., Cary, NC, USA).

\section{RESULTS}

\section{Patient Demographics}

A total of 902 patients were screened, and 871 patients were enrolled on the basis of the inclusion and exclusion criteria. Out of the enrolled patients, 654 (72.5\%) completed the study and 248 (27.5\%) patients prematurely discontinued from the study (Fig. 1). All the enrolled 871 patients were included in the safety analysis set (SAF) and $622(69.0 \%)$ were included in the EFF. The mean age of the study population was 50.9 years (range 19-73 years) and majority of them were male $(66.8 \%)$. The baseline characteristics of the study population are provided in Table 1 . The mean office SBP and DBP at baseline were $162.9 \mathrm{mmHg}$ and $97.3 \mathrm{mmHg}$, respectively. The mean duration of hypertension $(N=537, \quad N$ miss $=334)$ was 78.2 months. Out of 871 patients, 754 patients had CKD for 23.1 months on average and information for 117 patients were missing. Furthermore, 208 (24.4\%), 194 (22.8\%), 255 (29.9\%), $185(21.7 \%)$, and $10(1.2 \%)$ patients had stage $1 \quad\left(\mathrm{eGFR} \geq 90 \mathrm{~mL} / \mathrm{min} / 1.73 \mathrm{~m}^{2}\right)$, stage 2 (eGFR $60-89 \mathrm{~mL} / \mathrm{min} / 1.73 \mathrm{~m}^{2}$ ), stage 3 (eGFR $30-59 \mathrm{~mL} / \mathrm{min} / 1.73 \mathrm{~m}^{2}$ ), stage 4 (eGFR $\left.15-29 \mathrm{~mL} / \mathrm{min} / 1.73 \mathrm{~m}^{2}\right)$, and stage 5 (eGFR < $15 \mathrm{~mL} / \mathrm{min} / 1.73 \mathrm{~m}^{2}$ ) CKD, respectively, with data missing for 19 patients. The underlying causes of CKD are presented in Table S2 in the supplementary material. The common comorbidities observed in patients were hyperlipidemia (44.8\%), diabetes mellitus (32.1\%), cardiovascular disease $(12.5 \%)$, stroke $(10.0 \%)$, and hyperuricemia (41.0\%).

\section{Change in Office SBP from Baseline to Week 12}

After 12 weeks of nifedipine GITS $60 \mathrm{mg}$ treatment, patients showed a marked decrease in office SBP from baseline (Fig. 2). The mean SBP decreased from $162.9 \mathrm{mmHg}$ at baseline to $138.9 \mathrm{mmHg}$ at week 12 . The mean change in SBP was $-24.0 \mathrm{mmHg} \quad(95 \% \quad$ CI -25.32 , $-22.65 \mathrm{mmHg}$ ). After missing data were accounting for in sensitivity analysis, the mean change in SBP was - $23.9 \mathrm{mmHg} \quad(95 \%$ $\mathrm{CI}-25.25,-22.60 \mathrm{mmHg}$ ) at week 12 (Table 2).

\section{Change in DBP from Baseline to Week 12}

After 12 weeks of nifedipine GITS $60 \mathrm{mg}$ treatment, there was a marked decrease in DBP from baseline (Fig. 2). The mean DBP decreased from $97.3 \mathrm{mmHg}$ at baseline $(N=619)$ to $82.9 \mathrm{mmHg}$ after 12 weeks (mean change $-14.3 \mathrm{mmHg}$,

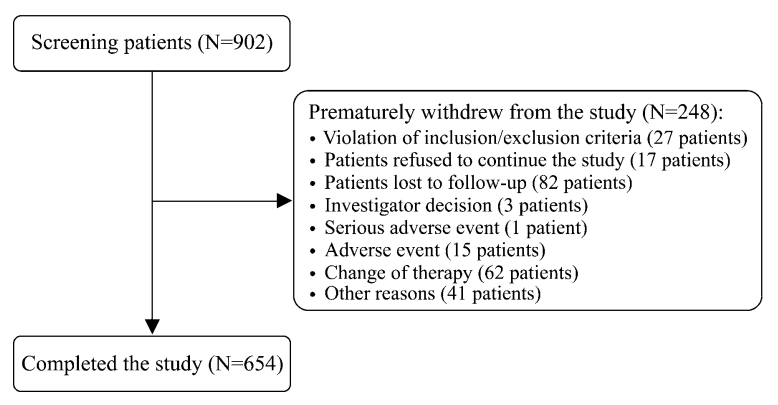

Fig. 1 Flowchart representing patient disposition 
Table 1 Baseline characteristics

\begin{tabular}{|c|c|c|}
\hline Variables & $N(N$ miss $)$ & SAF $(N=871)$ \\
\hline Age, years, mean $(\mathrm{SD})$ & $871(0)$ & $50.9(11.85)$ \\
\hline Male $(n[\%])$ & $871(0)$ & $582(66.8 \%)$ \\
\hline HR (beats per minute, mean [SD]) & $866(5)$ & $79.4(11.45)$ \\
\hline Height $(\mathrm{cm}$, mean $[\mathrm{SD}])$ & $868(3)$ & $167.2(7.93)$ \\
\hline Weight (kg, mean [SD]) & $868(3)$ & $73.44(15.075)$ \\
\hline BMI $\left(\mathrm{kg} / \mathrm{m}^{2}\right.$, mean $\left.[\mathrm{SD}]\right)$ & $868(3)$ & $26.12(4.107)$ \\
\hline Average office SBP (mmHg, mean [SD]) & $868(3)$ & $162.9(15.80)$ \\
\hline$<140 \mathrm{mmHg}(N[\%])$ & & $6(0.7 \%)$ \\
\hline $140-160 \mathrm{mmHg}(N[\%])$ & & $416(47.9 \%)$ \\
\hline$\geq 160 \mathrm{mmHg}(N[\%])$ & & $446(51.4 \%)$ \\
\hline Average office DBP (mmHg, mean $[\mathrm{SD}])$ & $868(3)$ & $97.3(11.55)$ \\
\hline \multicolumn{3}{|l|}{ Smoking history $(n[\%])$} \\
\hline Non-smoker & $869(2)$ & $590(67.7)$ \\
\hline Current smoker & & $204(23.4)$ \\
\hline Past smoker & & $75(8.6)$ \\
\hline \multicolumn{3}{|l|}{ Alcohol consumption $(n[\%])$} \\
\hline Alcoholics & $853(18)$ & $121(13.9)$ \\
\hline Non-alcoholics & & $732(84.0)$ \\
\hline \multicolumn{3}{|l|}{ Comorbidities history $(n[\%])$} \\
\hline Hyperlipidemia & & $390(44.8 \%)$ \\
\hline Diabetes mellitus & & $280(32.1 \%)$ \\
\hline Cardiovascular $(\mathrm{CV})$ disease & & $109(12.5 \%)$ \\
\hline Stroke & & $87(10.0 \%)$ \\
\hline Hyperuricemia & & $357(41.0 \%)$ \\
\hline \multicolumn{3}{|l|}{ Prior antihypertensives } \\
\hline ARBs & & $37 \%$ \\
\hline ACE inhibitors & & $9.6 \%$ \\
\hline$\beta$-blockers & & $21.9 \%$ \\
\hline \multicolumn{3}{|l|}{ Concomitant antihypertensives } \\
\hline ARBs & & $27.7 \%$ \\
\hline ACE inhibitors & & $4.0 \%$ \\
\hline
\end{tabular}


Table 1 continued

\begin{tabular}{lll}
\hline Variables & $\boldsymbol{N}(\boldsymbol{N}$ miss $)$ & SAF $(\boldsymbol{N}=\mathbf{8 7 1})$ \\
\hline$\beta$-blockers & $13.9 \%$ \\
\hline
\end{tabular}

$A C E$ angiotensin-converting enzyme, $A R B s$ angiotensin II receptor blockers, $B M I$ body mass index, $D B P$ diastolic blood pressure, $H R$ heart rate, $N$ number of patients, $N$ miss number of patients with missing data, $S A F$ safety analysis set, $S B P$ systolic blood pressure, $S D$ standard deviation

95\% CI - 15.27, - $13.37 \mathrm{mmHg}$ ). After missing values were accounted for by sensitivity analysis $(N=618)$, the mean change in DBP was $14.3 \mathrm{mmHg}$ (95\% CI - 15.28, - $13.39 \mathrm{mmHg}$ ), suggesting that the analysis was robust (Table 2).

\section{Change in SBP and DBP from Baseline to Week 12 in Different Patient Subgroups}

\section{Baseline SBP Subgroups}

At week 12, the mean SBP decreased from $150.3 \mathrm{mmHg}$ at baseline to $135.3 \mathrm{mmHg}$ in the SBP 140-160 mmHg group, and decreased from $174.7 \mathrm{mmHg}$ at baseline to $142.4 \mathrm{mmHg}$ in the $\mathrm{SBP} \geq 160 \mathrm{mmHg}$ group; the mean changes were $-14.9 \mathrm{mmHg} \quad(95 \% \quad \mathrm{CI}-16.20,-$ $13.68 \mathrm{mmHg}) \quad$ and $-32.3 \mathrm{mmHg} \quad(95 \%$ $\mathrm{CI}-34.18,-30.42 \mathrm{mmHg}), \quad$ respectively (Fig. 3). There was no change in mean change after accounting for missing data by sensitivity analyses. Furthermore, at week 12, the mean DBP decreased from $93.2 \mathrm{mmHg}$ at baseline to $82.2 \mathrm{mmHg}$ in the SBP $140-160 \mathrm{mmHg}$ group and decreased from $101.1 \mathrm{mmHg}$ at baseline to $83.7 \mathrm{mmHg}$ in the $\geq 160 \mathrm{mmHg}$ group; the mean changes were $-10.9 \mathrm{mmHg} \quad(95 \%$ $\mathrm{CI}-12.08,-9.73 \mathrm{mmHg}$ ) and $-17.4 \mathrm{mmHg}$ (95\% CI - 18.83, - $16.04 \mathrm{mmHg})$, respectively, and after missing data were accounted for, the mean changes were $-11.0 \mathrm{mmHg} \quad(95 \%$ $\mathrm{CI}-12.15,-9.82 \mathrm{mmHg}$ ) and $-17.4 \mathrm{mmHg}$ (95\% CI - 18.83, - $16.04 \mathrm{mmHg}$ ), confirming the robustness of the analysis (Table 3 ). The reduction of SBP and DBP was positively correlated with baseline BP.

\section{Stage of CKD Subgroups}

There was a marked decrease in SBP and DBP from baseline to week 12 irrespective of the CKD stage (Table S3 in the supplementary material). In patients with stage $1 \mathrm{CKD}(N=129)$, the mean SBP decreased from $160.4 \mathrm{mmHg}$ at baseline to $136.9 \mathrm{mmHg}$ at week 12 and the mean change in SBP was $-23.6 \mathrm{mmHg} \quad(95 \% \quad$ CI -26.28 , $-20.91 \mathrm{mmHg}$ ). The mean DBP decreased from $96.6 \mathrm{mmHg}$ at baseline to $82.9 \mathrm{mmHg}$ at week 12 with a mean change of $-13.7 \mathrm{mmHg}(95 \%$ CI $-15.48,-11.92 \mathrm{mmHg})$. In patients with stage 2 CKD $(N=133)$, the mean SBP decreased from $163.3 \mathrm{mmHg}$ at baseline to $137.2 \mathrm{mmHg}$ at week 12 with a mean change of $-26.0 \mathrm{mmHg}$ (95\% CI $-29.23,-22.85 \mathrm{mmHg})$. The mean DBP decreased from $97.3 \mathrm{mmHg}$ at baseline to $83.1 \mathrm{mmHg}$ at week 12 with a mean change of $-14.1 \mathrm{mmHg}$ (95\% CI - 16.30, $11.91 \mathrm{mmHg}$ ). In patients with stage 3 CKD $(N=198)$, the mean SBP decreased from $163.1 \mathrm{mmHg}$ at baseline to $139.0 \mathrm{mmHg}$ at week with a mean change of $-24.2 \mathrm{mmHg}(95 \%$ $\mathrm{CI}-26.56,-21.87 \mathrm{mmHg}$ ). Additionally, the mean DBP decreased from $97.7 \mathrm{mmHg}$ at baseline to $82.6 \mathrm{mmHg}$ at week 12 with a mean change of $-15.0 \mathrm{mmHg} \quad(95 \% \mathrm{CI}-16.9$, $-13.12 \mathrm{mmHg}$ ). In patients with stage $4 \mathrm{CKD}$ $(N=154)$, the mean SBP decreased from $164.3 \mathrm{mmHg}$ at baseline to $142.1 \mathrm{mmHg}$ at week 12 with a mean change of $-22.3 \mathrm{mmHg}$ (95\% CI $-25.00,-19.51 \mathrm{mmHg}$ ) and the mean DBP decreased from $96.9 \mathrm{mmHg}$ at baseline to $83.2 \mathrm{mmHg}$ at week 12 accounting for a mean change of $-13.7 \mathrm{mmHg} \quad(95 \% \quad \mathrm{CI}-$ 15.43, - $12.00 \mathrm{mmHg}$ ) (Fig. 4). Sensitivity analysis revealed that the results of the subgroup analysis were robust irrespective of the missing data. 


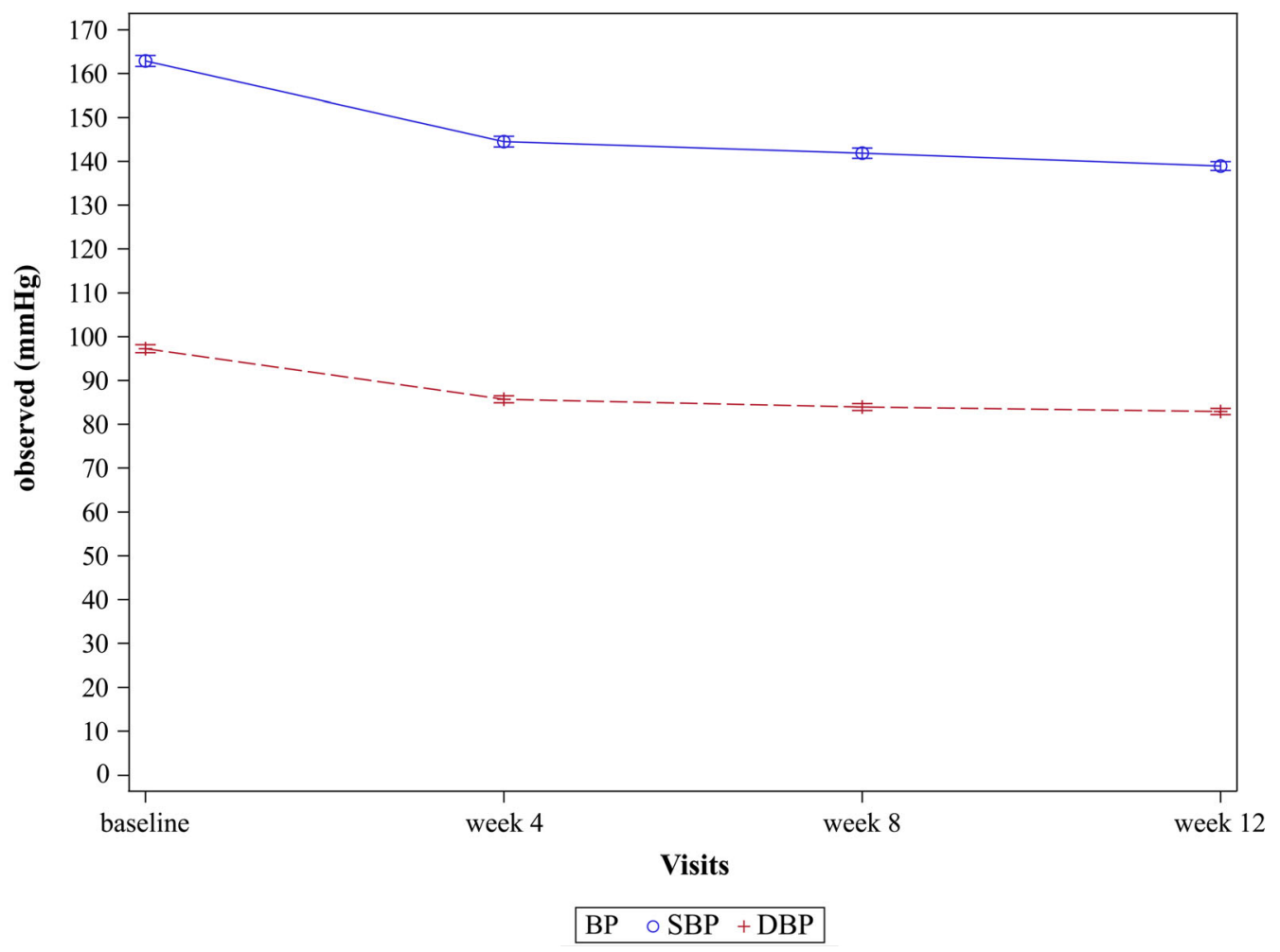

Fig. 2 Change in office SBP and DBP from baseline to week 12. BP blood pressure, DBP diastolic BP, SBP systolic BP

\section{SBP and DBP Control Rate at Week 12}

In the EFF, $49.7 \%$ and $50.3 \%$ of patients achieved SBP and DBP control goal, respectively, by analysis and sensitivity analyses, and the control rate $(95 \% \mathrm{CI})$ was $50.0 \%(46.1 \%$, $53.9 \%)$ by analysis and $50.3 \%(46.3 \%, 54.3 \%)$ by sensitivity analyses at week 12 (Table $S 4$ in the supplementary material).

\section{Adverse Events}

All the enrolled patients $(N=871)$ were included in SAF, the mean (standard deviation) duration of exposure to the study drug was 89.2 (39.99) days. On the basis of SAF, 8.3\% (72/871) of patients experienced 117 TEAEs, 2.6\% (23/ 871 ) of patients experienced 23 ADRs, $2.2 \%$ (19/ 871 ) of patients experienced 20 TEAEs leading to drug interruption, and no TEAE leading to death was reported (Table S5 in the supplementary material). The observed ADRs were mainly dizziness $(0.8 \%)$, generalized edema $(0.6 \%)$, and headache $(0.3 \%)$ (Table S6 in the supplementary material). We observed 16 SAEs in $1.7 \%(15 / 871)$ of patients (Table S7 in the supplementary material), and only 1 SAE (1/ $871,1 \%$, hyperkalemia) was considered as related to the study drug (no action was taken to the study drug and the event resolved on its own). No hypotension event was reported in any of the patients.

\section{DISCUSSION}

CKD is a life-threatening disease that results in ESRD and consumes substantial health resources [20]. In China, the prevalence of CKD in the general population increases gradually with age [5]. Uncontrolled hypertension is a risk factor for developing CKD, and is the second leading cause of ESRD in the USA $[21,22]$. Similarly, a 
Table 2 Change in office SBP and DBP from baseline to week 12 (EFF)

\begin{tabular}{llllll}
\hline Visits & $\boldsymbol{N}(\boldsymbol{N}$ miss) & $\begin{array}{l}\text { Office SBP }(\mathbf{m m H g} ; \\
\text { mean [SD] }\end{array}$ & $\begin{array}{l}\text { Change in SBP } \\
(\text { mean }[\mathbf{S D}])\end{array}$ & $\begin{array}{l}\text { DBP (mmHg; } \\
\text { mean [SD] })\end{array}$ & $\begin{array}{l}\text { Change in DBP } \\
(\mathbf{m e a n}[\mathbf{S D}])\end{array}$ \\
\hline Baseline & $619(3)$ & $162.9(15.82)$ & & $97.3(11.55)$ & \\
Week 4 & $561(61)$ & $144.5(14.88)$ & $-18.0(17.01)$ & $85.7(9.68)$ & $-11.2(11.41)$ \\
Week 8 & $505(117)$ & $141.9(13.48)$ & $-20.6(16.58)$ & $83.9(9.03)$ & $-13.0(11.61)$ \\
Week 12 & $618(4)$ & $138.9(12.79)$ & $-24.0(16.85)$ & $82.9(8.91)$ & $-14.3(12.00)$ \\
$\begin{array}{l}\text { Week 12 } \\
\text { sensitivity } \\
\text { analysis }\end{array}$ & $622(0)$ & $138.9(12.76)$ & $-23.9(16.81)$ & $82.9(8.88)$ & $-14.3(11.98)$ \\
\hline
\end{tabular}

$D B P$ diastolic blood pressure, $E F F$ efficacy analysis set, $N$ number of patients with available data, $N$ miss number of patients with missing data, $S B P$ systolic blood pressure, $S D$ standard deviation

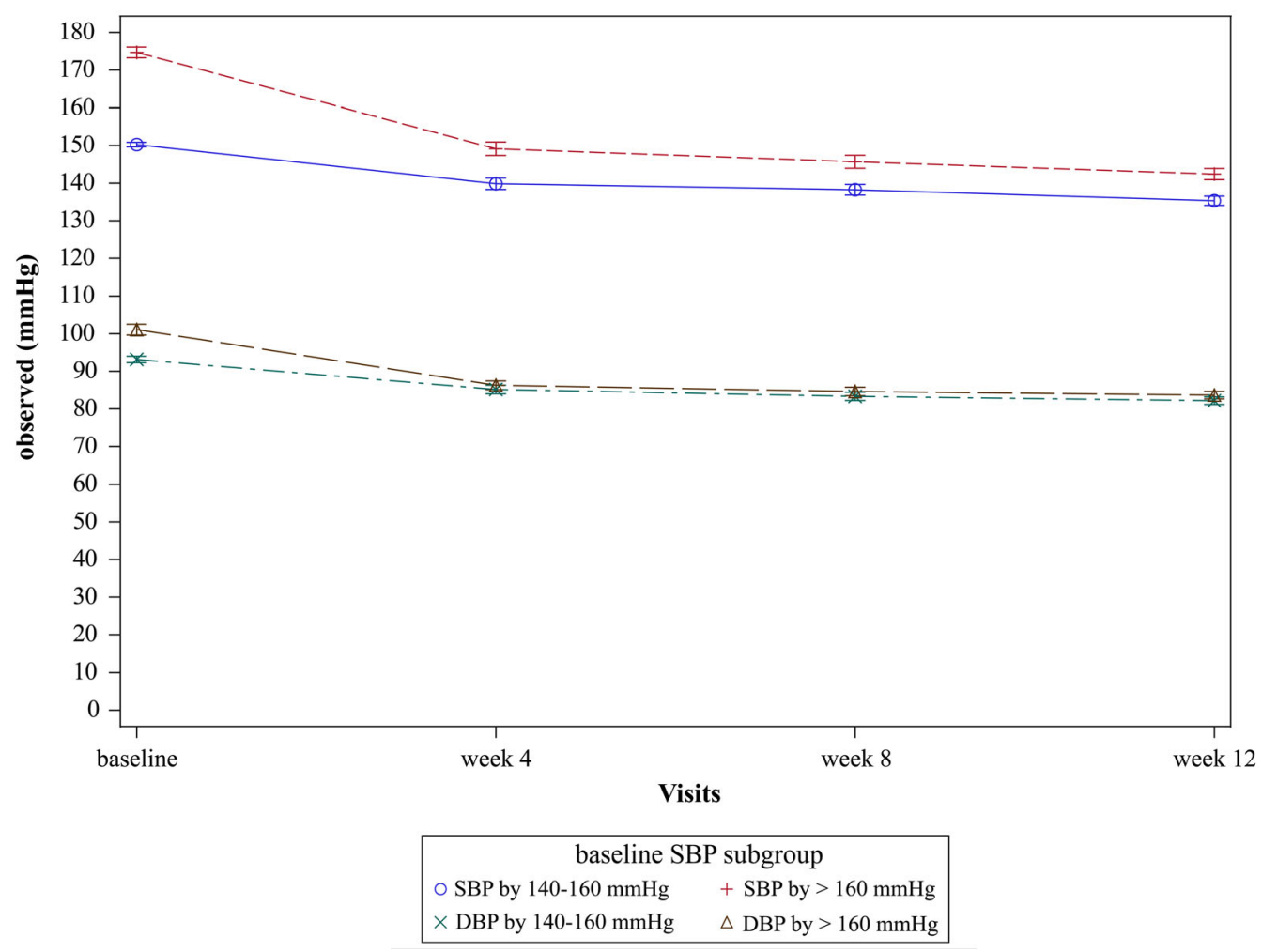

Fig. 3 Change in office SBP and DBP from baseline to week 12 in different patient subgroups. DBP diastolic blood pressure, SBP systolic blood pressure

decrease in eGFR leads to the exacerbation of uncontrolled hypertension due to volume expansion and increased systemic vascular resistance [4]. Multiple guidelines emphasize the importance of lowering BP to slow the progression of renal disease and reduce cardiovascular morbidity and mortality [23, 24]. Studies such as AASK and Rein-2 have 


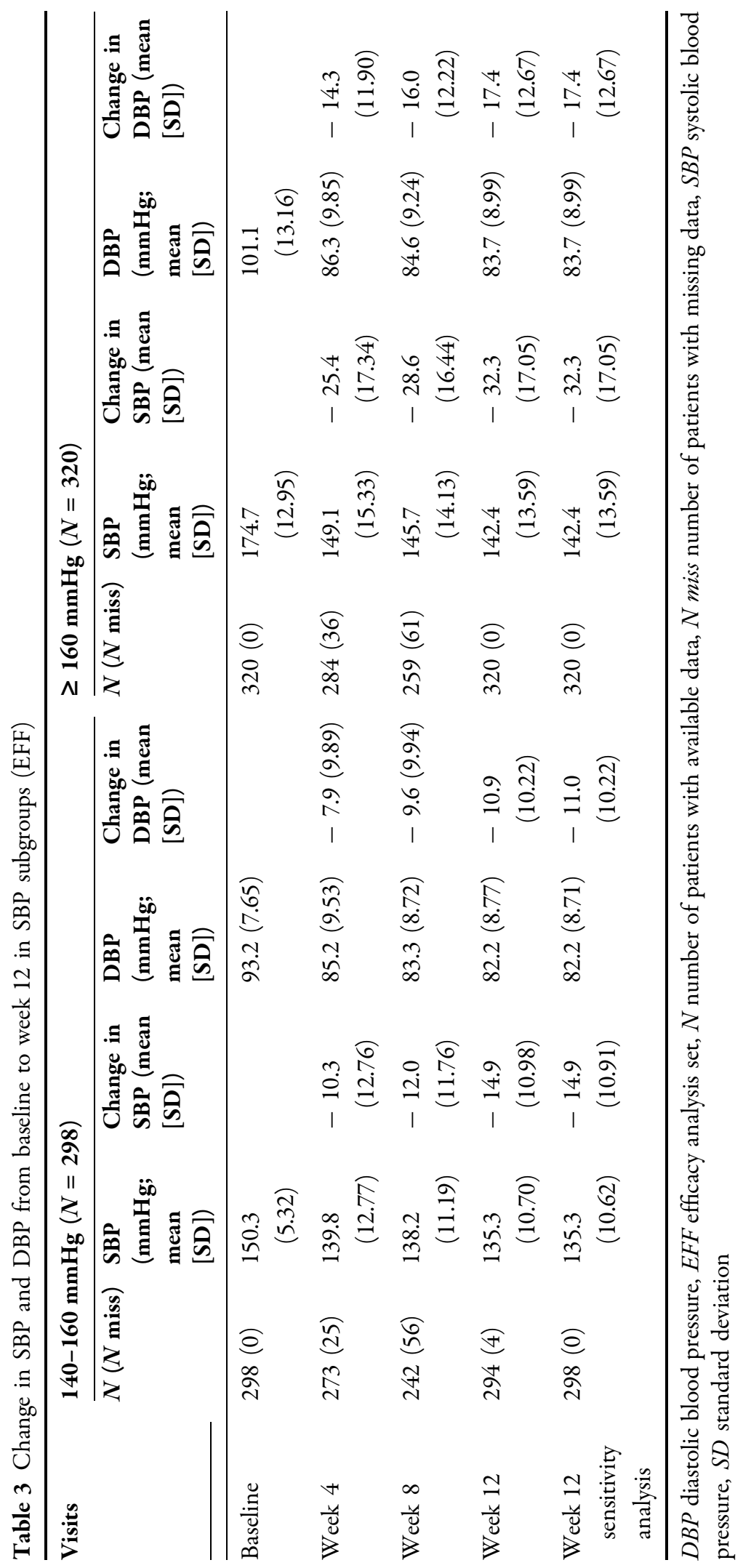




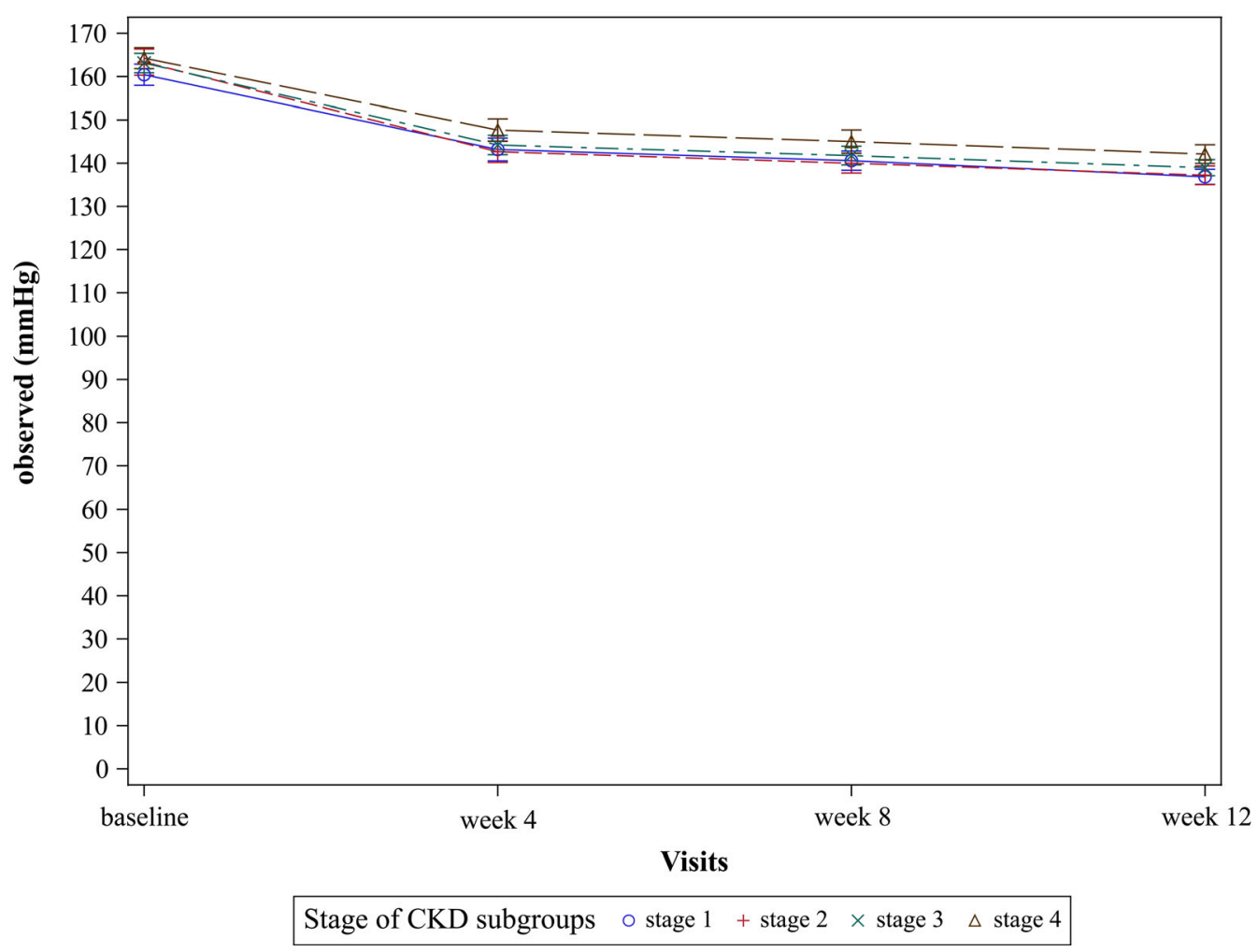

Fig. 4 Change in office SBP from baseline to week 12 (EFF, stage of CKD subgroups). CKD chronic kidney disease, EFF efficacy analysis set, SBP systolic blood pressure

confirmed the obvious benefits of stringent $\mathrm{BP}$ control in patients with CKD, which can reduce proteinuria, delay the decline of renal function, and improve the prognosis of patients with CKD $[25,26]$. This emphasizes the need for effective antihypertensive treatment options to delay the progression of CKD. However, achieving BP control is a challenge in patients with CKD and uncontrolled hypertension $[6,7]$.

Studies have shown that with increase in dosage, the magnitude of lowering BP with CCB monotherapy also increases $[18,27]$. Our study evaluated the effectiveness and tolerability of nifedipine GITS $60 \mathrm{mg}$ in a relatively large cohort of Chinese patients with CKD and uncontrolled hypertension and filled the data gap for high-dose CCB treatment in Chinese patients with CKD. A multicenter study in China showed that only $33.1 \%$ and $14.1 \%$ patients with CKD and hypertension achieved the target $\mathrm{BP}<140 / 90$ and $<130 / 80 \mathrm{mmHg}$, respectively [6]. In our study, we enrolled patients with CKD and uncontrolled hypertension, and the BP control goal followed the guidelines' recommendation: maintain an average office $\mathrm{SBP} / \mathrm{DBP}<140 / 90 \mathrm{mmHg}$, and maintain an average office SBP/DBP $<130$ / $80 \mathrm{mmHg}$ when urine albumin excretion was $\geq 30 \mathrm{mg} / 24 \mathrm{~h}$. After 12 weeks of nifedipine GITS $60 \mathrm{mg}$ treatment, we observed a remarkable reduction in office SBP and DBP with a control rate of $50.3 \%$, which is much higher than the previous BP control rate in patients with CKD [6]. Achieving BP control is challenging in patients with $\mathrm{CKD}$; the underlying cause for poor BP control might be due to physician's unawareness of guidelines and therapeutic inertia together with poor medication adherence and lifestyle modifications by patients. In the future studies, healthcare providers and patient interventions need to be established to address these causes. 
We also found some interesting outcomes in the subgroups analysis. In baseline SBP subgroups, we noted that mean change in SBP and DBP was related to the baseline SBP after 12 weeks nifedipine GITS $60 \mathrm{mg}$ treatment; the higher the baseline SBP was, the greater the BP reduction. This finding is consistent with previous findings where patients with higher SBP at baseline and treated with nifedipine GITS reported greater reduction in BP than in patients with a lower baseline SBP [28, 29]. In CKD stage subgroups, we observed a marked decrease in office SBP and DBP with conspicuous mean changes at week 12 irrespective of the CKD stage, and the mean change in SBP/DBP of each stage was basically consistent with the overall results. This means that the antihypertensive effect of nifedipine $60 \mathrm{mg}$ was not affected by CKD stage, which is a very important finding because we know that with successive CKD stages, the prevalence of hypertension in patients with non-dialysis CKD increases, but the control of hypertension decreases $(P<0.001)[6]$. In a multicenter study conducted by Cai et al., elderly adults with CKD stage $4(N=408)$ and stage $5(N=748)$ had difficulty in achieving BP control compared with those with patients with CKD stage $1(N=342)$ (CKD stage 4 , odds ratio $[\mathrm{OR}]=0.5, P=0.002$; CKD stage $5, \mathrm{OR}=0.4 ; P<0.001$ ) [30]. Previously conducted studies have also demonstrated the effectiveness of nifedipine GITS $60 \mathrm{mg}$ $[19,31,32]$. In the EXACT trail, a 20 -week, postmarketing surveillance study of the effectiveness and patient tolerability of nifedipine GITS 30 or $60 \mathrm{mg}$, the final BP readings after 20 weeks of treatment in the 30-mg group (141.5 \pm 0.4 / $84.8 \pm 0.2 \mathrm{mmHg})$ and $60-\mathrm{mg}$ group $(146.6 \pm 0.8 / 88.8 \pm 0.4 \mathrm{mmHg})$ were significantly decreased from baseline. The study also indicated a better reduction in $\mathrm{BP}$ with nifedipine GITS $60 \mathrm{mg}$ than GITS $30 \mathrm{mg}$ [19]. The INSIGHT study showed the effectiveness of nifedipine GITS $30 \mathrm{mg}$ in reducing BP from $173 / 99 \mathrm{mmHg}$ to $138 / 82 \mathrm{mmHg}$ [31]. Similarly, at week12, 30-60 mg/day nifedipine GITS significantly $(P<0.0001)$ reduced sitting SBP $(17 \pm 14 \mathrm{mmHg})$ and sitting DBP $(14 \pm 8 \mathrm{mmHg})$ in the MATH trial [32]. In another study, nifedipine GITS in doses of 30,
60 , or $90 \mathrm{mg}$ once daily was more effective than sustained-release propranolol in reducing standing $(P<0.005)$ and sitting SBP $(P<0.001)$ and DBP $(P<0.02)$ [33].

Nifedipine and other CCBs are associated with AEs such as edema, dizziness, and headache [34]. In previous studies, the rate of $\mathrm{AE}$ occurrence was low with nifedipine GITS $30 \mathrm{mg}$ monotherapy. In the study by Ueng et al., 1.6\% of the study population reported 286 AEs [34]. Nifedipine GITS $30 \mathrm{mg}$ also reported a low rate of SAE occurrence. In our study, the patients treated with nifedipine GITS $60 \mathrm{mg}$ showed great tolerability. ADRs were observed in $2.6 \%$ of patients and the most likely cause for these events may be associated with patients' concurrent conditions/underlying diseases and concomitant medications being taken. No event of hypotension or death occurred during the study.

Overall, owing to the availability of a limited number of studies with nifedipine GITS $60 \mathrm{mg}$ in the Chinese population, this evidence on nifedipine GITS $60 \mathrm{mg}$ might play an essential role in improving the hypertension management practice in patients with CKD, and offer a new option. The main strength of the study is its prospective nature, which minimizes the recall bias. However, the study also has some limitations. This is a single-arm study without any comparator/control arm. Comparison with a lower dose group of nifedipine would have made a better evaluation of the efficacy and safety of nifedipine GITS $60 \mathrm{mg}$. Moreover, being an observational study, it might be subject to known and unknown confounders and biases.

\section{CONCLUSION}

The results of this prospective observational study showed that nifedipine GITS $60 \mathrm{mg}$ is effective in reducing office SBP and DBP in Chinese patients with CKD and uncontrolled hypertension. The reduction of SBP/DBP was positively correlated with baseline $\mathrm{BP}$ and was not affected by different stages of CKD. In addition, analysis of the safety results revealed 
that nifedipine GITS $60 \mathrm{mg}$ was safe and well tolerated in the studied population.

\section{ACKNOWLEDGEMENTS}

We thank the participants of the study.

Funding. The study, the journal's Rapid Service Fee and the Open Access Fee were funded by Bayer Healthcare Company Ltd.

Medical Writing, Editorial, and Other Assistance. The authors acknowledge Bayer Healthcare Company Ltd. for managing the conduct of the study; Hangzhou Tigermed Consulting Co. Ltd. (Hangzhou, China) for data management and statistical support; Dr. Sunita Rana and Dr. Kaushik Subramanian (Indegene Pvt Ltd, Bengaluru, India) for providing medical writing assistance in the development of this manuscript, which was funded by Bayer Healthcare Company Ltd.

Authorship. All named authors meet the International Committee of Medical Journal Editors (ICMJE) criteria for authorship for this article, take responsibility for the integrity of the work as a whole, and have given their approval for this version to be published.

Authors' Contributions. All authors contributed to the development of the publication and maintained control over the final content.

Disclosures. Hua Xiao and Wenbin Song are employees of Bayer. Rong Lv, Jianghua Chen, Huamin Wang, Jijun Wang, Hong Cheng, Rong Li, Wei Li, Tao Zhang, Lixin Wei, Qinkai Chen, Jian Huang, Feng Yu, Shizhong Shen, Henglan WU, Cuihong Liu, Fuyuan Hong, Jie Liu, and Xiaoru Zhang have nothing to disclose.

Compliance with Ethics Guidelines. The study was approved by the ethics committee of First Affiliated Hospital, College of Medicine, Zhejiang University, 2016 Lun Shen No. (80), which is the master ethics committee. Approval was also provided by the institutional review board of the participating study centers
(Table S1). The study was conducted in accordance with the Helsinki Declaration of 1964 and its later amendments. All the patients provided written informed consent before study initiation.

Data Availability. The data sets generated during and/or analyzed during the current study are available from the corresponding author on reasonable request.

Open Access. This article is licensed under a Creative Commons Attribution-NonCommercial 4.0 International License, which permits any non-commercial use, sharing, adaptation, distribution and reproduction in any medium or format, as long as you give appropriate credit to the original author(s) and the source, provide a link to the Creative Commons licence, and indicate if changes were made. The images or other third party material in this article are included in the article's Creative Commons licence, unless indicated otherwise in a credit line to the material. If material is not included in the article's Creative Commons licence and your intended use is not permitted by statutory regulation or exceeds the permitted use, you will need to obtain permission directly from the copyright holder. To view a copy of this licence, visit http://creativecommons.org/licenses/bync/4.0/.

\section{REFERENCES}

1. GBD Chronic Kidney Disease Collaboration. Global, regional, and national burden of chronic kidney disease, 1990-2017: a systematic analysis for the Global Burden of Disease Study 2017. Lancet. 2020;395:709-33.

2. Fox CS, Larson MG, Leip EP, Culleton B, Wilson PWF, Levy D. Predictors of new-onset kidney disease in a community-based population. JAMA. 2004;291:844-50.

3. Tozawa M, Iseki K, Iseki C, Kinjo K, Ikemiya Y, Takishita S. Blood pressure predicts risk of developing end-stage renal disease in men and women. Hypertension. 2003;41:1341-5. 
4. Muntner P, Anderson A, Charleston J, et al. Hypertension awareness, treatment, and control in adults with CKD: results from the Chronic Renal Insufficiency Cohort (CRIC) Study. Am J Kidney Dis. 2010;55:441-51.

5. Zhang L, Wang F, Wang L, et al. Prevalence of chronic kidney disease in China: a cross-sectional survey. Lancet. 2012;379:815-22.

6. Zheng Y, Cai G-Y, Chen X-M, et al. Prevalence, awareness, treatment, and control of hypertension in the non-dialysis chronic kidney disease patients. Chin Med J (Engl). 2013;126:2276-80.

7. Kidney Disease: Improving Global Outcomes (KDIGO). KDIGO clinical practice guideline for the management of blood pressure in chronic kidney disease. J Kidney Int Suppl. 2012;2:337-414.

8. Armstrong C. JNC8 guidelines for the management of hypertension in adults. AFP. 2014;90:503-4.

9. Zheng Y. Study on the clinical characteristics and current status of hypertension in hospitalized patients with chronic kidney disease in China, vol. 27. Beijing: Chinese People's Liberation Army Medical College; 2012. p. 115-29.

10. Wang JG, Staessen JA, Gong L, Liu L. Chinese trial on isolated systolic hypertension in the elderly. Systolic Hypertension in China (Syst-China) Collaborative Group. Arch Intern Med. 2000;160: 211-20.

11. Liu L, Zhang Y, Liu G, et al. The Felodipine Event Reduction (FEVER) Study: a randomized long-term placebo-controlled trial in Chinese hypertensive patients. J Hypertens. 2005;23:2157-72.

12. Mancia G, De Backer G, Dominiczak A, et al. 2007 guidelines for the management of arterial hypertension: the task force for the management of arterial hypertension of the European Society of Hypertension (ESH) and of the European Society of Cardiology (ESC). J Hypertens. 2007;25:1105-87.

13. Khan KM, Patel J, Schaefer TJ. Nifedipine. StatPearls [Internet]. Treasure Island: StatPearls; 2020. http:// www.ncbi.nlm.nih.gov/books/NBK537052/. Accessed 26 Jan 2021.

14. Pontremoli R, Leoncini G, Parodi A. Use of nifedipine in the treatment of hypertension. Expert Rev Cardiovasc Ther. 2005;3:43-50.

15. Chung M, Reitberg DP, Gaffney M, Singleton W. Clinical pharmacokinetics of nifedipine gastrointestinal therapeutic system. A controlled-release formulation of nifedipine. Am J Med. 1987;83:10-4.
16. Schneider R, Stolero D, Griffel L, Kobelt R, Brendel E, Iaina A. Pharmacokinetic profile of nifedipine GITS in hypertensive patients with chronic renal impairment. Drugs. 1994;48(Suppl 1):16-21 (discussion 21-22).

17. Expert consensus on the application of long-acting dihydropyridine calcium channel blockers in chronic kidney disease and hypertension. Chin Gen Pract. 2006;9:20.

18. Park JB, Shin J-H, Kim D-S, et al. Safety of the uptitration of nifedipine GITS and valsartan or lowdose combination in uncontrolled hypertension: the FOCUS study. Clin Ther. 2016;38:832-42.

19. Toal CB, Mahon WA, Barnes C, Burelle D. Nifedipine gastrointestinal therapeutic system (GITS) for hypertensive patients in a primary care setting: results of the Extended Release Adalat Canadian Trial (EXACT). Clin Ther. 1997;19:924-35.

20. Cai G, Chen X. Hypertension in patients with CKD in China: clinical characteristics and management. Front Med. 2017;11:307-9.

21. Botdorf J, Chaudhary K, Whaley-Connell A. Hypertension in cardiovascular and kidney disease. Cardiorenal Med. 2011;1:183-92.

22. Segura J, Ruilope LM. Hypertension in moderate-tosevere nondiabetic CKD patients. Adv Chronic Kidney Dis. 2011;18:23-7.

23. Chobanian AV, Bakris GL, Black HR, et al. The seventh report of the Joint National Committee on prevention, detection, evaluation, and treatment of high blood pressure: the JNC 7 report. JAMA. 2003;289:2560-72.

24. National Kidney Foundation. K/DOQI clinical practice guidelines for chronic kidney disease: evaluation, classification, and stratification. Am J Kidney Dis. 2002;39:S1-266.

25. Wright JT, Bakris G, Greene T, et al. Effect of blood pressure lowering and antihypertensive drug class on progression of hypertensive kidney disease: results from the AASK trial. JAMA. 2002;288: 2421-31.

26. Ruggenenti P, Perna A, Loriga G, et al. Blood-pressure control for renoprotection in patients with non-diabetic chronic renal disease (REIN-2): multicentre, randomised controlled trial. Lancet. 2005;365:939-46.

27. Mizuno H, Hoshide S, Tomitani N, Kario K. Comparison of ambulatory blood pressure-lowering effects of higher doses of different calcium antagonists in uncontrolled hypertension: the Calcium Antagonist Controlled-Release High-Dose Therapy 
in Uncontrolled Refractory Hypertensive Patients (CARILLON) study. Blood Press. 2017;26:284-93.

28. Kjeldsen SE, Cha G, Villa G, Mancia G, DISTINCT Investigators. Nifedipine GITS/candesartan combination therapy lowers blood pressure across different baseline systolic and diastolic blood pressure categories: distinct study subanalyses. J Clin Pharmacol. 2016;56:1120-9.

29. Motaweih AK, Usova E, Hussain W, Dello Z, Schmidt B, Petri T. Effectiveness of combination therapy with nifedipine GITS: a prospective, 12-week observational study (AdADOSE). BMC Cardiovasc Disord. 2015;15:35.

30. Cai G, Zheng Y, Sun X, Chen X, Survey of Prevalence, Awareness, and Treatment Rates in Chronic Kidney Disease Patients with Hypertension in China Collaborative Group. Prevalence, awareness, treatment, and control of hypertension in elderly adults with chronic kidney disease: results from the survey of prevalence, awareness, and treatment rates in chronic kidney disease patients with hypertension in China. J Am Geriatr Soc. 2013;61: 2160-7.
31. Brown MJ, Palmer CR, Castaigne A, et al. Morbidity and mortality in patients randomised to doubleblind treatment with a long-acting calcium-channel blocker or diuretic in the International Nifedipine GITS study: Intervention as a Goal in Hypertension Treatment (INSIGHT). Lancet. 2000;356:366-72.

32. Krakoff LR, Bravo EL, Tuck ML, Friedman CP. Nifedipine gastrointestinal therapeutic system in the treatment of hypertension. Results of a multicenter trial. The Modern Approach to the Treatment of Hypertension (MATH) study group. Am J Hypertens. 1990;3:318S-325S.

33. Frishman WH, Garofalo JL, Rothschild A, Rothschild M, Greenberg SM, Soberman J. The nifedipine gastrointestinal therapeutic system in the treatment of hypertension. Am J Cardiol. 1989;64: $65 \mathrm{~F}-69 \mathrm{~F}$.

34. Ueng K-C, Ningling S, El Maksod A, Hung K-Y, Yuehui Y. Efficacy and tolerability of long-acting nifedipine GITS/OROS monotherapy or combination therapy in hypertensive patients: results of a 12-week international, prospective, multicentre, observational study. Clin Drug Investig. 2011;31: 631-42. 